\title{
Stimulus novelty and intraseries primacy in GSR adaptation
}

GSR records were obtained for four groups of 20 Ss. Group 1 was presented with a series of four different lights (amber, blue, green, and white) appearing 20 times each, in apparent random order. The procedure was similar for the other three groups except that in group 2, a novel stimulus (a red light) appeared instead of the sixth amber light; in group 3, it appeared instead of the 11 th amber light; and, in group 4, it appeared instead of the 1 hth amber light. Typical GSR adaptation phenomena were observed in all groups. The introduction of the novel stimulus appeared to have no effect on the course of GSR adaptation.

In previous studies (Fried, Korn, \& Welch, 1966), GSR records were obtained from Ss while they were presented with a series of 80 stimuli (four lights alternating in apparently random sequence). A novel stimulus consisting of a light not previously presented was substituted in place of one of the original four lights: white, amber, green and blue. This novel stimulus was a red light.

It was found, in the above study, that the introduction of the novel stimulus, while reported verbally by all $\mathrm{Ss}$, and spontaneously by $40 \%$ of them, failed to produce change in the GSR adaptation records sufficient to differentiate them, statistically, from the adaptation curves for a control group.

It was concluded that changes in GSR adaptation, reported by Allen, Hill, and Wickens (1963), and by Berlyne, Craw, Salapatek, and Lewis (1963) in support of the concept of the orienting response do not necessarily lead to the conclusion that stimulus novelty and stimulus differentness are parallel psychological variables.

It is, however, entirely possible that the novelty of stimuli, as indicated by the response measure, varies with the place in the stimulus series where it is introduced. This possibility has been anticipated by Hayes, Bronzaft, Bloch, and Welch (1964).

The present study is an attempt to determine whether the evocation of an orienting response depends upon the temporal place where a novel stimulus is introduced in a stimulus series.

\section{Method}

The method of serial stimuli yields rapid and persistent GSR adaptation (Korn \& Welch, 1962; Fried, Korn \& Welch, 1966). The Ss are exposed to a series of similar stimuli (four differently colored lights) that are presented in apparent random sequence. Attention is maintained, while GSR responsivity is reduced.
ROBERT FRIED, LIVINGSTON WELCH AND MIRIAM FRIEDMAN HUNTER COLLEGE OF THE CITY UNIVERSITY OF NEW YORK ${ }^{1}$

Apparatus. GSR records were obtained with a custom built Pathometer coupled to a Texas Instruments Rectiriter.

Visual stimuli were presented by six $60 \mathrm{w}$ lamps with cellulose acetate filters. The lights were projected on a common milkglass aperture 1-1/2 in. in diameter and appeared to the Ss as a circular source of light in the wall. The four hues, blue, green, white and amber, were programmed to appear with a probability of .25 , and the Ss could not learn the sequence.

Hunter Timers controlled the stimulus duration (7.5 sec.) and the interstimulus time (.01 sec.).

Subjects. Eighty naive female undergraduates were used. There were $20 \mathrm{Ss}$ in each of three experimental groups and one control group.

Procedure. Each $\mathrm{S}$ was seated in a small room and finger electrodes were attached. The room was darkened and $\mathrm{S}$ was instructed to look at the changing lights and refrain from unnecessary movement.

Five min. were allowed to elapse before the stimuli were presented, e.g., trial 1 .

In the control group, the four hues, blue, green, white and amber, were presented until each had appeared 20 times. In experimental group 1, a red light was substituted for the sixth amber light in the series. And, in experimental groups 2 and 3 , the red light was substituted for the eleventh and sixteenth a mber light, respectively.

The red light was the novel stimulus and it never appeared in any other position, or at any other time.

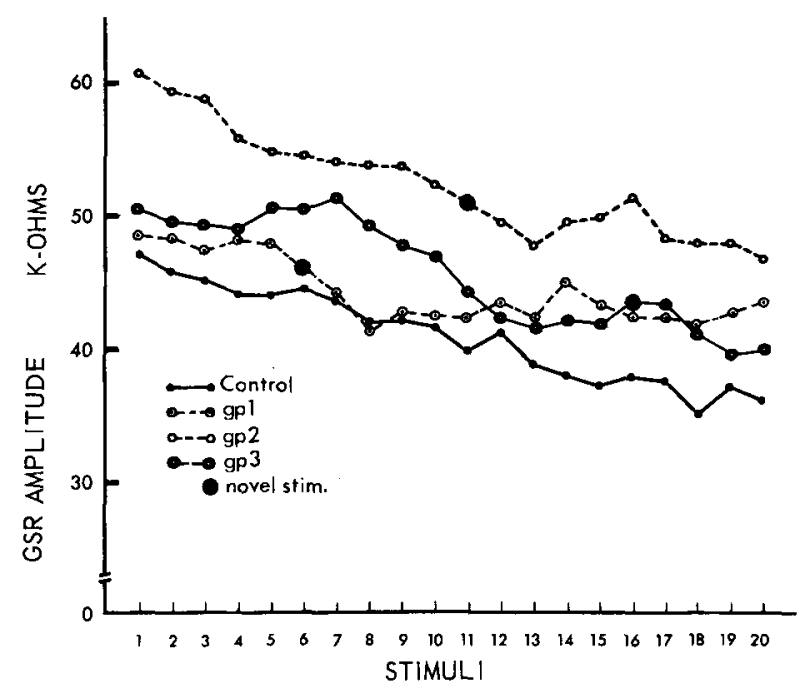

Fig. 1. GSR Mean Amplitude: adaptation to amber stimuli. 


\section{Results}

The data, resistance in ohms during each presentation of the amber light, is presented in Fig. 1. For each S, there were 20 such presentations. The amber light is arbitrarily designated the critical stimulus since, by analogy, the CS in conditioning is designated by $\mathrm{E}$ and is seldom the only stimulus to which $\mathrm{S}$ is exposed.

Note that GSR adaptation phenomena were observed. And, virtually no difference exists between the adaptation curves for the experimental and control groups. Analysis of variance indicates homogeneity $(F=.05)$ of trends.

\section{Discussion}

It appears that the novel stimulus had no evident effect on the temporal course of GSR adaptation. The contention that intraseries primacy, e.g., the position, in the series closer to the first trials, determines the effect of the novel stimulus in the evocation of an orienting response is unsubstantiated by the data in the present study.

It is interesting to note that McGinnies (1949) reports S's responsivity to stimuli which, he contends, they do not perceive, per se. While, in the present study, it was found that Ss failed to respond to stimuli which, many report spontaneously, they do perceive. It is entirely likely that observation of orienting responses is more dependent upon methodological differences than upon stimulus differences.

\section{References}

Allen, C., Hill, F., \& Wickens, D. The orienting reflex as a function of the interstimulus interval of compount stimuli. J. exp. Psychol., 1963, 65, 309-316.

Berlyne, D., Craw, M., Salapatek, J., \& Lewis, J. Novelty, complexity, incongruity, intrinsic motivation and the GSR. J. exp. Psychol., 1963, 66, 560-567.

Hayes, R., Bronzaft, A., Bloch, A., \& Welch, L. Intra-series primacy and the orienting reflex of the GSR. J. exp. Psychol. 1964, 58, 107-113.

Fried, R., Korn, S., \& Welch, L. The effect of change in sequential visual stimuli on GSR adaptation. $J$. exp. Psychol., in press (due Sept. 1966).

Korn, S., \& Welch, L. Conditioned responses: fact and artifact. J. Psychol., 1962, 53, 301-309.

\section{Note}

1. Also The Payne Whitney Clinic, New York Hospital.

(Accepted for publication, August 17, 1966.) 